\title{
COMPARATIVE STUDY OF CYCLIC FATIGUE RESISTANCE OF PROTAPER GOLD, ONESHAPE, AND TF FILES
}

\author{
Shady Ali Hussein * and Amr Ahmed Bayoumi **
}

\begin{abstract}
Aim: The purpose of this study was to compare the resistance to cyclic fatigue of three nickeltitanium (NiTi) endodontic instruments from Protaper Gold (PTG), OneShape (OS), and Twisted files (TF).

Methodology: A total of 45 nickel-titanium instruments were tested and divided into 3 experimental groups $(\mathrm{n}=15)$ : group 1, Protaper Gold (F2 25/.08); group 2, OneShape (25/.06) file; and group 3, Twisted file (25/.06). The testing device was specially designed for this experiment. The time and cycles to failure were calculated. The data were compared for differences by using 2-way analysis of variance $(\mathrm{p}<0.05)$.
\end{abstract}

Results: Statistical analysis revealed that PTG showed the statistically significantly highest mean cyclic fatigue value, while TF showed statistically significantly lower mean cyclic fatigue value. OS system showed the statistically significantly lowest mean cyclic fatigue value.

Conclusions: ProTaper Gold files demonstrated significantly higher cyclic fatigue resistance than OneShape and Twisted files, while OneShape files revealed the lowest cyclic fatigue resistance. The enhanced alloy properties of ProTaper Gold may be the main reason for this difference.

\section{INTRODUCTION}

Root canals shaping is highly affected by mechanical properties of endodontic instruments. Procedural errors such as transportation, ledge, zipping, stripping, and perforation result from deviation from the canal curvature. The main mechanical properties of instruments that affect their performance in curved canals are flexibility and cyclic fatigue resistance.
The fracture of NiTi rotary files occur due to torsional failure or flexural failure ${ }^{(1,2)}$. Torsional failure usually occurs when the file tip is locked inside the root canal while the shank continues rotation. File unwinding, reverse winding, and reverse winding with tightening of the spirals often occurs with torsional failure. Flexural failure occurs due to metal fatigue where the rotary file rotates freely inside the canal curvature with repeated tension and compression cycles at point of

\footnotetext{
* Lecturer of Endondontics, Ain-Shams University

** Lecturer of Endondontics, Misr International University
} 
maximum curvature until fracture occurs ${ }^{(3,4,5)}$. This type of failure exhibits no specific patterns of plastic deformation under microscopic examination unlike the torsional failure. The manufacturing process of NiTi instruments usually results in internal residual stresses and surface defects that affect the overall instrument strength ${ }^{(6)}$. In unused NiTi instruments, suface defects and work hardening have been reported. Some improvements have been employed to minimize the effect of machining defects.

ProTaper Gold files (PTG) (Dentsply Tulsa Dental Specialties, Tulsa, OK) are newly introduced files that exhibit improved mechanical properties because of their innovative metallurgy, which had 2-stage specific transformation behavior and high $\mathrm{A}_{\mathrm{f}}$ temperatures ${ }^{(7)}$. PTG files have changing helical angle as well as convex triangular cross section.

Single file concept has been recently introduced. OneShape (Micro Méga, Besançon, France), a typical single-file instrument, manufactured from conventional austenite NiTi alloy, and operates in continuous rotation ${ }^{(9,10)}$. It was claimed by the manufacturer that OneShape file exhibits improved shaping ability and cleaning efficacy. However, the cyclic fatigue resistance and the force generated by OneShape files in preparing curved canals is not fully investigated ${ }^{(11)}$.

The TF files (Sybron Dental Specialties, Orange, $\mathrm{CA})$ represents another improvement in the NiTi instruments manufacturing. TF files have a constant tip size of \#25 with tapers of .04, .06, 0.8, .10, and .12. It was reported that the R-phase heat treatment, special surface treatment and twisting of the metal significantly increased the file cyclic fatigue resistance $^{(12)}$.

The purpose of this study was to evaluate the cyclic fatigue resistance of 3 different NiTi instruments in artificial canals: Protaper Gold (PTG), OneShape (OS), and Twisted Files (TF). The hypothesis is that the new generation of instruments made of modified NiTi alloys possess better mechanical properties when compared with instruments manufactured from conventional NiTi alloy.

\section{Methodology}

Fifteen PTG F2 (25/.08), 15 OneShape (25/.06), and $15 \mathrm{TF}(25 / .06)$ files were included in the present study.

\section{Testing Device}

The testing device was specially designed for this experiment by using a modification of the device used by Haikel et al ${ }^{(13)}$. The device consisted of a steel base attached to a specifically machined holder that position the hand-piece in a precise relationship to the cyclic flexural fatigue testing block. The cyclic flexural fatigue testing block consisted of $1 \mathrm{~mm}$ deep and wide groove that was machined into a stainless steel block. The block had a curve with a $5 \mathrm{~mm}$ radius. The angle of the cyclic fatigue testing block to the horizontal plane was adjusted such that when the tested file was mounted in the hand-piece, it conformed to the curve without the need for a covering cylinder. The resulting angle of curvature was 51 degrees according to the method of Schneider ${ }^{(14)}$. The files were mounted in the handpiece and positioned to the same point in the testing block. (Figure 1)

The files were divided into 3 experiment groups, and the following procedures were performed:

1. Group 1: Protaper Gold (F2 25/.08). The files in this group were used with the X-Smart endodontic motor mounted on a cyclic fatigue test device at $300 \mathrm{rpm}$ and $3.1 \mathrm{~g} / \mathrm{cm}$ torque in rotation mode until the fracture occurred.

2. Group 2: OneShape (25/.06). The files in this group were used with the $\mathrm{X}$-Smart endodontic motor mounted on a cyclic fatigue test device at $400 \mathrm{rpm}$ and $2 \mathrm{~g} / \mathrm{cm}$ torque in rotation mode until the fracture occurred.

3. Group 3: Twisted file (25/.06). The files in this group were used with the X-Smart endodontic motor mounted on a cyclic fatigue test device at 
$500 \mathrm{rpm}$ and $2.5 \mathrm{~g} / \mathrm{cm}$ torque in rotation mode until the fracture occurred.

\section{Testing procedures}

The time to fracture was recorded using digital chronometer. Using the time data, the numbers of cycles to failure (NCFs) were calculated according to the following formula: $\mathrm{NCFs}=$ revolutions per minute $\mathrm{x}$ time to fracture (seconds)/60 $(15,16,17)$.

Numerical data were explored for normality by checking the data distribution and using Kolmogorov-Smirnov and Shapiro-Wilk tests. Data showed parametric (normal) distribution. Data were represented as mean, standard deviation (SD) and 95\% Confidence interval for the mean $(95 \% \mathrm{CI})$ values. One-way ANOVA test was used to study compare between the three groups. Bonferroni's post-hoc test was used for pair-wise comparisons when ANOVA test is significant.

The significance level was set at $\mathrm{P} \leq 0.05$. Statistical analysis was performed with $\mathrm{IBM}^{\circledR}$ SPSS $^{\circledR}$ Statistics Version 20.

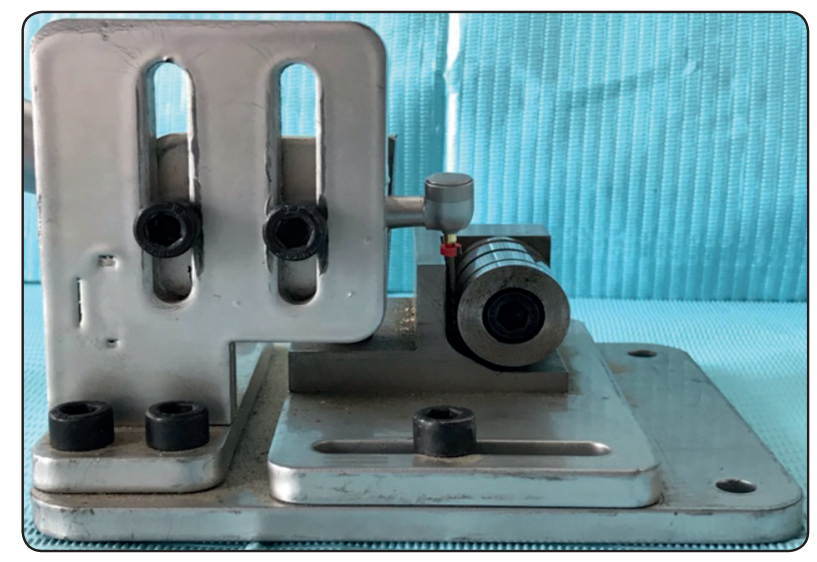

Fig. (1) Showing the cyclic fatigue testing device

\section{RESULTS}

There was a statistically significant difference between the three systems $(P$-value $<0.001$, Effect size $=0.889)$. Pair-wise comparisons between the systems revealed that PTG showed the statistically significantly highest mean cyclic fatigue value. TF showed statistically significantly lower mean cyclic fatigue value. OS system showed the statistically significantly lowest mean cyclic fatigue value.

TABLE (1) Descriptive statistics and result of oneway ANOVA test for comparison between cyclic fatigue in the three groups.

\begin{tabular}{|c|c|c|c|c|c|c|}
\hline \multirow{2}{*}{ System } & \multirow{2}{*}{ Mean } & \multirow{2}{*}{ SD } & \multicolumn{2}{|c|}{$95 \% \mathrm{CI}$} & \multirow{2}{*}{$P$-value } & \multirow{2}{*}{$\begin{array}{c}\text { Effect } \\
\text { size (Eta } \\
\text { squared) }\end{array}$} \\
\hline & & & $\begin{array}{l}\text { Lower } \\
\text { bound }\end{array}$ & $\begin{array}{l}\text { Upper } \\
\text { bound }\end{array}$ & & \\
\hline $\mathrm{TF}$ & $408.8^{\mathrm{B}}$ & 27 & 388 & 429.5 & \multirow{3}{*}{$<0.001^{*}$} & \multirow{3}{*}{0.889} \\
\hline OS & $144.1^{\mathrm{C}}$ & 35.9 & 116.5 & 171.7 & & \\
\hline PTG & $1052.9^{\mathrm{A}}$ & 258.5 & 813.8 & 1291.9 & & \\
\hline
\end{tabular}

*: Significant at $P \leq 0.05$, Different superscripts are statistically significantly different

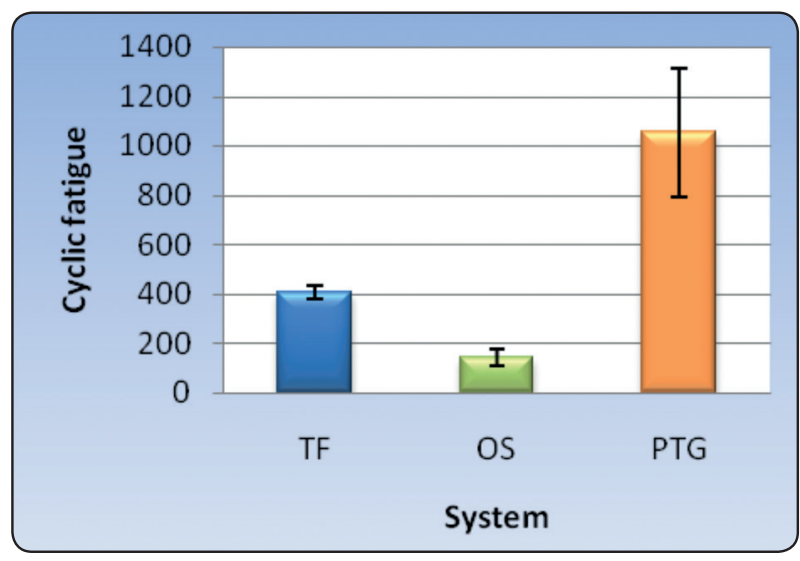

Fig. (2): Bar chart representing mean and standard deviation values for cyclic fatigue in the three groups.

\section{DISCUSSION}

Files with high fracture resistance are preferred during root canal preparation. Instrument failure may not only affect clinical outcomes ${ }^{(18)}$, but also may produce procedural mishaps ${ }^{(19)}$. During shaping the file is subjected to repeated cycles of tension and compression leading to crack propagation originating from manufacturing flaws that function as initial crack nuclei ${ }^{(20)}$. Microcracks subsequently expands deeper through the material until complete file separation occurs ${ }^{(21)}$. All files exhibit surface 
irregularities as well as inner defects resulting from the manufacturing process which directly affects the fracture strength of endodontic instruments ${ }^{(22,23)}$.

Human teeth were used in several studies in the experimental design ${ }^{(24,25)}$. However, it is impossible to control the amount of stresses in the rotatingbending area of the instrument when used in human canals. Moreover, different root canal curvature from tooth to tooth is considered another important variation. Also, there will always be a combination of torsional stress and cyclic fatigue when human root canals are used. To avoid these biases, an artificial metallic block with a groove was used.

In the present study, a device was used to hold the hand-piece to eliminate the interference of operatorinduced tensions on endodontic instruments during the fatigue test ${ }^{(26)}$. The stainless steel cyclic fatigue testing block had a curve with a $5 \mathrm{~mm}$ radius and consisted of $1 \mathrm{~mm}$ deep and wide groove in order to standardize the entire length of the canal, the length of curvature radius, and the length of the arc. A lubricant was used in-order to allow the instruments to rotate within the canal without significant resistance during the cyclic fatigue test ${ }^{(27)}$.

It was previously reported that the instruments size affected the cyclic fatigue resistance of the rotary files, and it was recommended to test the files with similar diameters to compare the effects of the design and manufacturing properties of the novel instruments more accurately ${ }^{(28)}$. In the present study, files in all groups have a tip diameter equivalent to size $0.25 \mathrm{~mm}$.

PTG Showed statistically significant the highest cyclic fatigue resistance, it might be speculated that alloy properties of the PTG files were the main factor for the different mechanical performance of the instruments. In addition, thermomechanical treatment of PTG instruments leads to the 2-stage transformation behavior (austenite-reverse phase martensite) in which the reverse phase is considered a potential martensitic phase with improved resistance to fatigue ${ }^{(29)}$.
In this study TF 25.06 showed a higher fatigue resistance than OS files, representing the major role of the manufacturing process in increasing the resistance to fatigue of NiTi rotary instruments. TF is manufactured with a twisting method of a heat-treated wire (R-phase), which maintains the natural grain structure that would result in slower crack initiation and propagation, also an absence of transverse-running machining marks as a result of electropolishing ${ }^{(30)}$.

According to the results of the present study, OS files showed the lowest cyclic fatigue resistance among the tested NiTi files. In previous studies, the files made of controlled memory were reported to have higher cyclic fatigue resistance than those made of the conventional NiTi alloy ${ }^{(31,32)}$. The fact that the same results were found in the present study is believed to originate from the production of OS files using the conventional NiTi alloy.

On the basis of above mentioned information and within the limitations of this study, it could be considered that PTG files could be used more safely in severely curved canals because of their higher cyclic fatigue resistance.

\section{CONCLUSION}

ProTaper Gold files demonstrated significantly higher cyclic fatigue resistance than OneShape and Twisted files, while OneShape files revealed the lowest cyclic fatigue resistance. The enhanced alloy properties of ProTaper Gold may be the main reason for this difference.

\section{REFERENCES}

1. Sattapan B, Nervo GJ, Palamara JEA, et al. Defects in rotary nickel-titanium files after clinical use. J Endod 2000;26:161-5.

2. Ullmann CJ, Peters OA. Effect of cyclic fatigue on static fracture loads in ProTaper nickel-titanium rotary instruments. J Endod 2005;31:183-6.

3. Peters OA. Current challenges and concepts in the preparation of root canal systems: a review. J Endod 2004;30: 559-67. 
4. Pettiette MT, Metzger Z, Phillips C, Trope M. Endodontic complications of root canal therapy performed by dental students with stainless-steel K-files and nickel-titanium hand files. J Endod 1999;25:230-4.

5. Bergmans L,Van Cleynenbreugel J, Wevers M, Lambrechts P. Mechanical root canal preparation with NiTi rotary instruments: rationale, performance and safety. Status report for the Am J of Dentistry. Am J Dent 2001;14:324-33.

6. Gambarini G. Cyclic fatigue of Profile rotary instruments after prolonged clinical use. Int Endod J 2001;34:386-9.

7. Hieawy A, Haapasalo M, Zhou H, et al. Phase transformation behavior and resistance to bending and cyclic fatigue of ProTaper Gold and ProTaper Universal instruments. J Endod 2015; 41:1134-8.

8. Ruddle CJ. The ProTaper technique. Endod Topics 2005;10:187-90.

9. Bürklein S, Benten S, Schäfer E. Shaping ability of different single-file systems in severely curved root canals of extracted teeth. Int Endod J. 2013; 46(6): 590-7.

10. Bürklein S, Benten S, Schäfer E. Quantitative evaluation of apically extruded debris with different single-file systems: Reciproc, F360 and OneShape versus Mtwo. Int Endod J. 2014; 47(5): 405-9.

11. Capar ID, Ertas H, Arslan H. Comparison of cyclic fatigue resistance of novel nickel-titanium rotary instruments. Aust Endod J. 2014; 41(1): 24-8.

12. Oh SR, Chang SW, Lee Y, Gu Y. A comparison of nickeltitanium rotary instruments manufactured using different methods and cross-sectional areas: ability to resist cyclic fatigue. Oral Surg Oral Med Oral Pathol Oral Radiol Endod 2010;109:622-8.

13. Haikel Y, Serfaty R, Bateman G, Senger B, Allemann C. Dynamic and cyclic fatigue of engine-driven rotary nickel titanium endodontic instruments. J Endod 1999; 25, 434-40.

14. Schnieder WE. A comparison of canal preparations in straight and curved root canals. Oral Surg 1971;32: 27-5.

15. Ozyurek T. Cyclic fatigue resistance of Reciproc, WaveOne, and WaveOne Gold Nickel-titanium instruments. J Endod 2016; 42:1536-1539.

16. Gundogar M and Ozyurek T. Cyclic fatigue resistance of OneShape, HyFlex EDM, WaveOne Gold, and Reciproc Blue Nickel-titanium instruments. J Endod 2017; 43:11921196.

17. Keskin C, Inan U, Guler DH, Kalyoncuoglu E. Cyclic fatigue resistance of XP-Endo Shaper, K3XF, and Protaper Gold Nickel-titanium instruments. J Endod 2018; 44:11641167.
18. Crump MC, Natkin E. Relationship of broken root canal instruments to endodontic case prognosis: a clinical investigation. J Am Dent Ass 1970;80:1341-7.

19. Al-Fouzan KS. Incidence of rotary ProFile instrument fracture and the potential for by passing in vivo. Int Endod J 2003;36:864-7.

20. McNicholls JL, Brookes PC, Cory JS. NiTi fatigue behaviour. J Appl Phys 1981;52: 7442- 4.

21. Christ HJ. Fundamental mechanisms of fatigue and fracture. Student Health Technology Information 2008;133:56-67.

22. Anderson ME, Price JW, Parashos P. Fracture resistance of electropolished rotary nickel-titanium endodontic instruments. J Endod 2007;33:1212-26.

23. Wei X, Ling J, Jiang J, et al. Modes of failure of ProTaper nickel-titanium rotary instruments after clinical use. J Endod 2007;33:276-9.

24. Daugherty DW, Gound TG, Comer TL. Comparison of fracture rate, deformation rate, and efficiency between rotary endodontic instruments driven at $150 \mathrm{rpm}$ and $350 \mathrm{rpm}$. J Endod 2001;27:93-5.

25. Ankrum MT, Hartwell GR, Truitt JE. K3 Endo, ProTaper, and ProFile systems: breakage and distortion in severely curved roots of molars. J Endod 2004;30:234-7.

26. Pruett JP, Clement DJ, Carnes DL Jr. Cyclic fatigue testing of nickel-titanium endodontic instruments. J Endod 1997;23:77-85.

27. Inan U, Aydin C, Tunca YM. Cyclic fatigue of ProTaper rotary nickel-titanium instruments in artificial canals with 2 different radii of curvature. Oral Surg Oral Med Oral Pathol Oral Radiol Endod 2007;104:837-40.

28. Capar ID, Ertas H, Arslan H. Comparison of cyclic fatigue resistance of nickel- titanium coronal flaring instruments. J Endod 2014;40:1182-5.

29. Elnaghy A, Elsaka S. Mechanical properties of ProTaper Gold nickel-titanium rotary instruments. Int Endod J 2016;49:1073-8.

30. Kim HC, Yum J, Hur B, Shun-Pan GC. Cyclic fatigue and fracture characteristics of ground and twisted nickel-titanium rotatory files. J Endod 2010;36: 147-52.

31. Campbell L, Shen Y, Zhou HM, Haapasalo M. Effect of fatigue on torsional failure of nickel-titanium controlled memory instruments. J Endod 2014;40:562-5.

32. Braga LC, Silva AC, Buono VT, de Azevedo Bahia MG. Impact of heat treatments on the fatigue resistance of different rotary nickel-titanium instruments. J Endod 2014; 40:1494-7. 